\title{
Optimization and characterisation of bonding of piezoelectric transducers using anisotropic conductive adhesive
}

\section{Citation for published version:}

Cummins, G, Gao, J, McPhillips, R, Watson, D, Cochran, S \& Desmulliez, MPY 2017, Optimization and characterisation of bonding of piezoelectric transducers using anisotropic conductive adhesive. in 2017 IEEE International Ultrasonics Symposium (IUS)., 8092114, IEEE International Ultrasonics Symposium, IEEE, International Ultrasonics Symposium 2017, Washington D.C., District of Columbia, United States, 6/09/17. https://doi.org/10.1109/ULTSYM.2017.8092114

\section{Digital Object Identifier (DOI): \\ 10.1109/ULTSYM.2017.8092114}

Link:

Link to publication record in Heriot-Watt Research Portal

Document Version:

Peer reviewed version

Published In:

2017 IEEE International Ultrasonics Symposium (IUS)

Publisher Rights Statement:

(C) 2017 IEEE. Personal use of this material is permitted. Permission from IEEE must be obtained for all other uses, in any current or future media, including reprinting/republishing this material for advertising or promotional purposes, creating new collective works, for resale or redistribution to servers or lists, or reuse of any copyrighted component of this work in other works.

\section{General rights}

Copyright for the publications made accessible via Heriot-Watt Research Portal is retained by the author(s) and / or other copyright owners and it is a condition of accessing these publications that users recognise and abide by the legal requirements associated with these rights.

\section{Take down policy}

Heriot-Watt University has made every reasonable effort to ensure that the content in Heriot-Watt Research Portal complies with UK legislation. If you believe that the public display of this file breaches copyright please contact open.access@hw.ac.uk providing details, and we will remove access to the work immediately and investigate your claim. 


\section{Optimization and Characterisation of Bonding of Piezoelectric Transducers using Anisotropic Conductive Adhesive}

\author{
G. Cummins, J. Gao, D.E. Watson, M.P.Y. Desmulliez \\ Multimodal Sensing and Micromanipulation Centre \\ School of Engineering and Physical Sciences \\ Heriot-Watt University \\ Edinburgh, UK, EH14 4AS \\ Email: G.Cummins@hw.ac.uk
}

\author{
R. McPhillips, S. Cochran \\ Medical and Industrial Ultrasonics Group \\ School of Engineering \\ University of Glasgow \\ Glasgow, UK, G12 8QQ
}

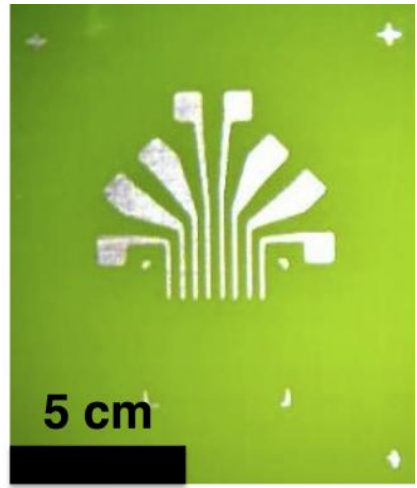

\begin{abstract}
Bonding technology using anisotropic conductive paste shows great promise to achieve the denser integration schemes that are required for the application of high resolution ultrasonic imaging. A design of experiments has been carried out to characterize and optimize a flip-chip bonding technology that utilizes a novel, magnetically aligned anisotropic conductive paste. This optimized process has the potential to implement more reliable and electrically conductive, fine pitch bonding for the production of high density ultrasound transducer arrays in needle devices.
\end{abstract}

Keywords-anisotropic conductive adhesive; flip-chip bonding; high frequency ultrasound; design of experiments

\section{INTRODUCTION}

It is well known that higher frequency of operation of ultrasound transducers enables high resolution imaging. For example, an ultrasound transducer operating above $15 \mathrm{MHz}$ is capable of achieving resolutions better than $200 \mu \mathrm{m}$ [1]. Such resolutions can improve the accuracy of surgical interventions and are of increasing interest in medicine. However, higher frequency operation results in increased attenuation and consequently decreased penetration depth. The resulting low penetration depth of the image requires that the transducer be operated close to the tissue of interest, which is commonly achieved by packaging the high-frequency transducers directly into surgical tools. The limited real-estate available within these tools calls for miniaturization of the transducer and denser integration.

Whereas miniaturization of the transducers is possible with manufacturing techniques borrowed from the semiconductor industry, challenges exist in the creation of a reliable interconnection scheme, capable of producing high density electrical connections between the transducers and their external electronics. Commonly used interconnection technologies such as wire bonding are not feasible when working with arrays with a large number of elements. Moreover, in the case of transducers integrated into needles, the medical requirement of small gauges (G16 or above) prohibits wire bonding interconnect above a certain array size. The lack of suitable integration technology limited many earlier attempts
FIG. 1 IMAGE OF PCB TEST STRUCTURE

at ultrasound transducers array in a needle to single element transducer [2] or using unsuitable packaging solutions [3].

A more suitable integration solution, capable of meeting these constraints is the use of magnetically aligned, anisotropic conductive paste (ACP)[4] to electrically connect the sensing array electrodes to fine pitch, flexible printed circuit board (FPCB). ACPs are composed of fine electrically conductive particles uniformly dispersed in an adhesive matrix. The ACP forms electrical connections through the conductive particles, while the cured adhesive ensures the mechanical integrity and strength of the bond. This technology has many attractive properties, which include (1) isolation of the electrical connections from one another along the volume of the paste line, (2) reduced temperature curing compared to thermocompression or eutectic bonding, (3) no flux residues and (4) no under filling [5], [6].

This paper builds upon previously reported work [7], [8] and describes the characterization and optimization process of that low temperature bonding technology for use in the production of miniaturized ultrasound systems to ensure increased interconnect yield. The development of a reliable integration technology suitable to produce a $15 \mathrm{MHz}$ ultrasound transducer requires greater understanding of the underlying 
physics and the selection of process values that are compatible with dimensional ( $<100 \mu \mathrm{m}$ interconnect pitch) and manufacturing (low temperature, low pressure) constraints.

\section{METHOD}

\section{A. Bonding Experiments}

Initial experiments consisted of bonding two rigid PCB substrates, an example of which is shown in Fig. 1, forming a copper daisy chain electrical test structure with $200 \mu \mathrm{m}$ track width and $200 \mu \mathrm{m}$ pitch. An FR4 board substrate was used due to its low cost and wide applicability. The bond between the aligned PCBs is formed using an intermediate layer of ACP.

$\mathrm{ZTACH}^{\mathrm{TM}}$ low temperature, thermally cured ACP (Sunray Scientific, USA) [4] was manually dispensed at room temperature onto a $50 \mu \mathrm{m}$ thick stencil before being forced through to the PCB surface. This ACP is a suspension of $1 \mu \mathrm{m}$ diameter, silver-coated ferromagnetic beads within an epoxy resin. During curing of the epoxy, the beads align themselves along a uniform magnetic field applied perpendicularly to the PCB surface, forming thereby conductive tracks between the PCBs. Magnetic alignment for the desired conductive path is achieved using a magnetic jig with an average magnetic flux density of $2.7 \mathrm{mT}$.

Aligning and bonding of the test PCB was carried out using a MAT 6400 die bonder (MAT Ltd, Israel) operated in a flipchip configuration mode. The bonded substrates were placed in a Gallenkamp Plus II oven (Gallenkamp, UK) and left to cure at $150^{\circ} \mathrm{C}$ for 15 minutes Though this temperature exceeds the Curie temperature of commonly used piezoelectric materials, it has been demonstrated that reducing the temperature to $80^{\circ} \mathrm{C}$ and increasing the cure time to 3 hours results in a similar thermal budget such that it could be eventually used with piezoelectric transducer. The PCB stack is placed under the magnetic jig during curing.

24 hours after curing the resistance of the daisy chain test structures was measured via two-probe measurement with a handheld multimeter (Fluke, USA). Electrical continuity and resistance values along the conductive path formed between copper electrodes on opposite PCBs were checked and measured for all connections.

\section{B. Design of Experiments}

The use of a full factorial Design of Experiments (DoE) enables the identification of the sensitivity of the bonding process to alterations of various parameters and the effect of interactions between these parameters on the result. The bonding parameters have a substantial effect on interconnect reliability and conductance. The selection of optimal values for these parameters is complicated, as it can vary depending on the adhesive [9] and substrate properties.

Three factors - the bonding force, bonding duration and stencil slit width - were considered the most important based on past experience. The bonding force acting on the conductive particles has a significant effect on the contact area between the pads and the particles. If the bonding force is too low the conductive particles will not be able to form a continuous conductive path between the connecting pads. If the bonding force is too high the particles will fracture, leading to the
TABLE I: EXPERIMENTAL MATRIX AND RESULTS OF ACA OPTIMIZATION

\begin{tabular}{|c|c|c|c|c|c|c|}
\hline & & & & & $\begin{array}{c}\text { Copper } \\
\text { Pads }\end{array}$ & \\
\hline $\begin{array}{l}\text { Exp. } \\
\text { No. }\end{array}$ & $\begin{array}{c}\text { Parameter } \\
\text { Set }\end{array}$ & $\begin{array}{c}\text { Stencil } \\
\text { Width } \\
(\mathrm{mm})\end{array}$ & $\begin{array}{c}\text { Bond. } \\
\text { Force } \\
(g)\end{array}$ & $\begin{array}{c}\text { Bond. } \\
\text { Time } \\
(s)\end{array}$ & $\bar{R}(\Omega)$ & $\sigma_{R}$ \\
\hline 1 & 7 & 1 & 300 & 10 & $2.6 \mathrm{E}+03$ & $4.3 \mathrm{E}+03$ \\
\hline 2 & 2 & 0.3 & 300 & 50 & $2.5 \mathrm{E}+31$ & $4.3 \mathrm{E}+31$ \\
\hline 3 & 4 & 1 & 100 & 10 & $1.6 \mathrm{E}+01$ & $2.5 \mathrm{E}+01$ \\
\hline 4 & 6 & 1 & 100 & 50 & $5.0 \mathrm{E}+31$ & $5.0 \mathrm{E}+31$ \\
\hline 5 & 1 & 1 & 300 & 50 & $5.0 \mathrm{E}+31$ & $5.0 \mathrm{E}+31$ \\
\hline 6 & 3 & 0.3 & 100 & 50 & $8.5 \mathrm{E}-01$ & $1.7 \mathrm{E}-01$ \\
\hline 7 & 5 & 0.3 & 300 & 10 & $5.0 \mathrm{E}+31$ & $5.0 \mathrm{E}+31$ \\
\hline 8 & 8 & 0.3 & 100 & 10 & $8.5 \mathrm{E}+00$ & $1.3 \mathrm{E}+01$ \\
\hline 9 & 3 & 0.3 & 100 & 50 & $2.5 \mathrm{E}+31$ & $4.3 \mathrm{E}+31$ \\
\hline 10 & 5 & 0.3 & 300 & 10 & $2.7 \mathrm{E}+00$ & $1.1 \mathrm{E}+00$ \\
\hline 11 & 2 & 0.3 & 300 & 50 & $5.0 \mathrm{E}+31$ & $5.0 \mathrm{E}+31$ \\
\hline 12 & 6 & 1 & 100 & 50 & $9.3 \mathrm{E}-01$ & $1.3 \mathrm{E}-01$ \\
\hline 13 & 7 & 1 & 300 & 10 & $1.7 \mathrm{E}+00$ & $8.8 \mathrm{E}-01$ \\
\hline 14 & 8 & 0.3 & 100 & 10 & $5.0 \mathrm{E}+31$ & $5.0 \mathrm{E}+31$ \\
\hline 15 & 4 & 1 & 100 & 10 & $5.3 \mathrm{E}+00$ & $5.6 \mathrm{E}+00$ \\
\hline 16 & 1 & 1 & 300 & 50 & $2.5 \mathrm{E}+31$ & $4.3 \mathrm{E}+31$ \\
\hline 17 & 5 & 0.3 & 300 & 10 & $2.5 \mathrm{E}+31$ & $4.3 \mathrm{E}+31$ \\
\hline 18 & 8 & 0.3 & 100 & 10 & $1.1 \mathrm{E}+01$ & $1.5 \mathrm{E}+01$ \\
\hline 19 & 7 & 1 & 300 & 10 & $1.3 \mathrm{E}+06$ & $2.2 \mathrm{E}+06$ \\
\hline 20 & 3 & 0.3 & 100 & 50 & $2.5 \mathrm{E}+31$ & $4.3 \mathrm{E}+31$ \\
\hline 21 & 1 & 1 & 300 & 50 & $1.4 \mathrm{E}+00$ & $1.2 \mathrm{E}+00$ \\
\hline 22 & 2 & 0.3 & 300 & 50 & $3.5 \mathrm{E}+00$ & $3.9 \mathrm{E}+00$ \\
\hline 23 & 6 & 1 & 100 & 50 & $7.5 \mathrm{E}+31$ & $4.3 \mathrm{E}+31$ \\
\hline 24 & 4 & 1 & 100 & 10 & $1.4 \mathrm{E}+01$ & $7.1 \mathrm{E}+00$ \\
\hline
\end{tabular}

disruption of the formation of a continuous electrical path. Ideally the force should be sufficient such that conductive particles should be deformed just before the metallic layers begin to fracture [6], [10]. The force at which this occurs has been shown to provide the largest contact areas, and therefore a lower average contact resistance. The value of this force varies, depending on factors such as particle size, material composition and others. The bonding force was controlled on the MAT 6400 die bonder through the use of an integrated, calibrated load cell. An equally important factor is the bonding duration, which refers to the period during which the ACP particles are subjected to the bonding force. Finally, changing stencil slit width causes increased paste area, which increases the chance of formation of conductive paths as well as mechanically stronger bonds. The fractional factorial DOE matrix is shown in Table I.

The ideal bonding process should result in a reproducible and low contact resistance. The four measurements of the resistance taken during each experiment was used to calculate the average value and the standard deviation resulting from that combination of parameters. The main effects ( $1^{\text {st }}$ order effects) and interaction matrix ( $2^{\text {nd }}$ order effects) were calculated for both the average and standard deviation of the resistance as shown in Fig 2. Initial analysis of the results show that width of the bonding duration, then the stencil slit and bonding duration have a more dominant effect than the bonding force. The decrease in average resistance with reduced bonding time can be explained by also observing that reduction in bonding force and bond time decreases the standard deviation of the resistance. This could be attributed to the deformed conductive particles fracturing under loads of $300 \mathrm{~g}$ or large bonding times creating a poor and variable conductive path. Thereby a reduction in bonding time prevents fracture and ensures low and reproducible contact resistance, which is expected due to the 

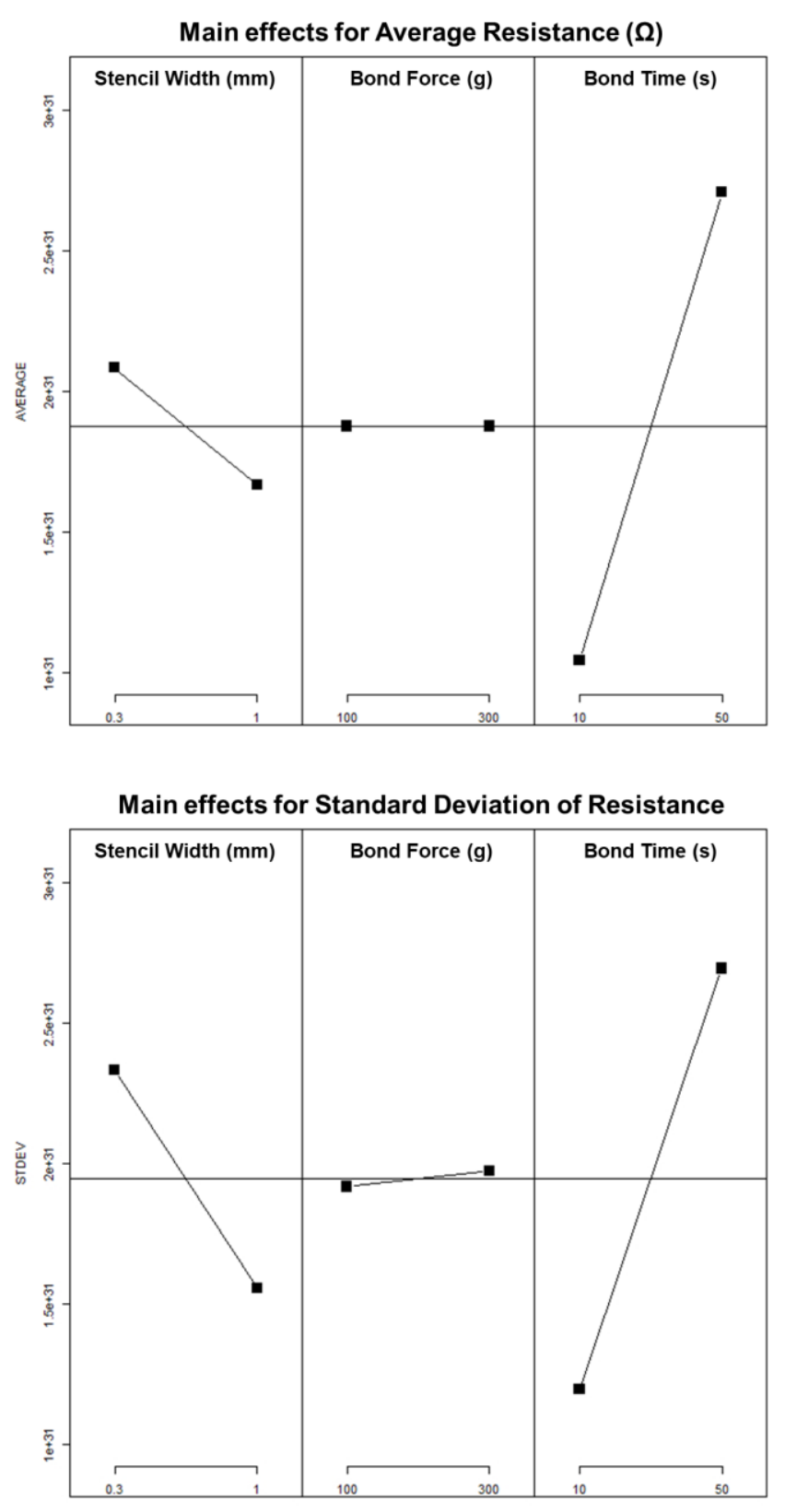

Interaction Plot for Average Resistance ( $\Omega$ )

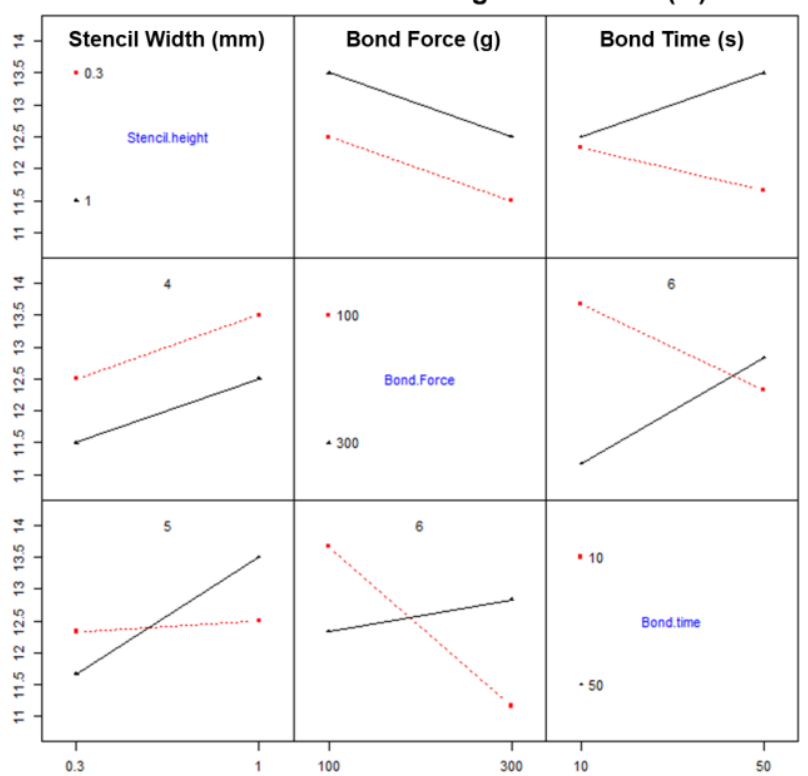

Interaction Plot for Standard Deviation of Resistance

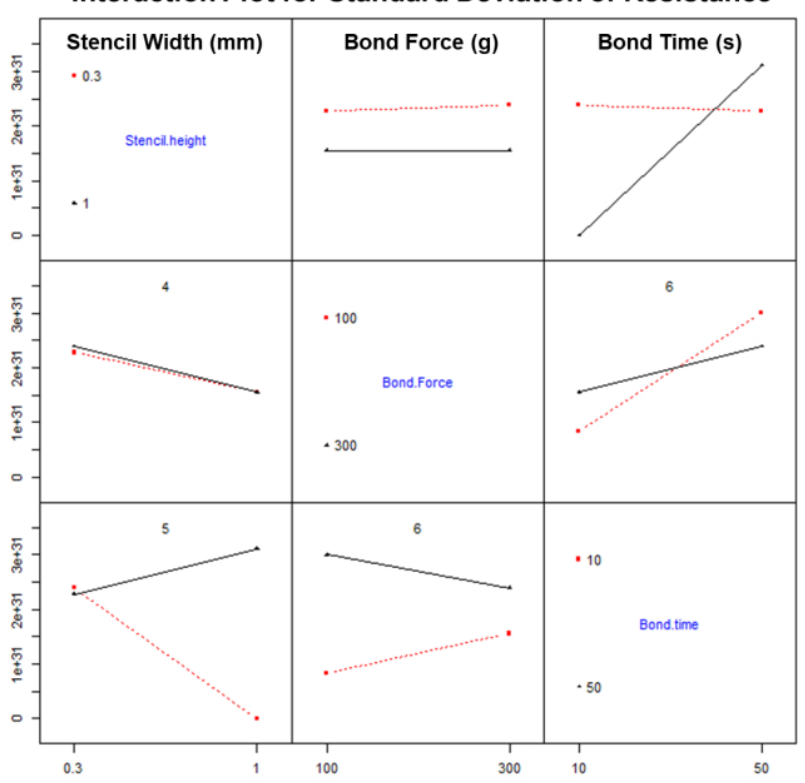

FIG. 2. MAIN EFFECT AND INTERACTION PLOTS FOR AVERAGE RESISTANCE VALUES AND STANDARD DEVIATION RESPONSES

larger contact area between the intermediate film of paste and the electrical pads. Increasing stencil width results in a reduction in the average resistance.

The $2^{\text {nd }}$ order effects for both standard deviation and average resistance shows no interaction between the bonding force and stencil widths. These parameters act independently of one another. However, both the bonding force and stencil width show interaction with the bonding time for both the average and standard deviation of the resistance. The strong interaction between bond force and time is not unexpected.

The interactions between stencil width and bonding time show that the process variability can be reduced using a short bonding time if a large stencil width is used, with changing bond time having a minimal $2^{\text {nd }}$ order effect if a short stencil width is utilized. The use of a larger $50 \mathrm{~s}$ bonding time shows an increase in variability no matter what stencil width is used. This can also be explained by the increased risk of fracturing conductive particles when held under load for longer periods of time.

Analysis of the results of the experimental matrix showed that, for a bonding force of $100 \mathrm{~g}$, stencil width of $1 \mathrm{~mm}$ and bonding time of $10 \mathrm{~s}$, a good conductive bond was consistently formed for all 72 measurements. The mean electrical resistance of this bond between the copper electrodes was measured to be approximately $12 \Omega$, this resistance is an order of magnitude greater than expected but it may be attributed to the presence of a thin layer of oxide on the copper surface. The good reproducibility and low resistance achieved with this set of 
parameters agrees with what has been observed from the main effect and interaction plot matrix for both the average and standard deviation values of the resistance.

\section{CONCLUSION}

This initial DOE analysis of the effect of process parameters such as bonding force, bonding time and stencil width on the quality and variability of a conductive bond generated between two copper electrodes and an intermediate layer of magnetically aligned ACP demonstrated an improvement of the yield of the bonds formed between piezoelectric, high frequency ultrasound transducers and flexible PCBs. The experimental matrix highlighted the sensitivity of this process with respect to the bonding time and amount of paste applied. This information will lead to more reliable integration processes, useful for the development of ultrasound transducer in needle applications.

\section{ACKNOWLEDGMENT}

This work was supported by the UK Engineering and Physical Sciences Research Council (EPSRC) through the Programme Grant entitled "Sonopill: minimally invasive gastrointestinal diagnosis and therapy", grant no. EP/K034537/1 and EP/K034537/2. The authors also acknowledge the financial contribution of the UK Medical Research Council through its Confidence in Concept programme (MRC-CiC3/036) and the support of the Edinburgh \& Lothian Health Foundation.

\section{REFERENCES}

[1] G. R. Lockwood, D. H. Turnbull, D. A. Christopher, and F. S. Foster, "Beyond $30 \mathrm{MHz}$ - applications of high-frequency ultrasound imaging," IEEE Eng. Med. Biol. Mag., vol. 15, pp. 60-71, 1996.

[2] T. Irie et al., "Tissue imaging using the transmission of 100-MHz-range ultrasound through a fused quartz fiber," in IEEE International Ultrasonics Symposium, IUS, 2013, pp. 2010-2013.

[3] A. L. Bernassau et al., "Microfabrication of electrode patterns for highfrequency ultrasound transducer arrays," IEEE Trans. Ultrason. Ferroelectr. Freq. Control, vol. 59, no. 8, pp. 1820-1829, 2012.

[4] Sunray Scientific, "Sunray Scientific Website." [Online]. Available: http://www.sunrayscientific.com/. [Accessed: 22-Aug-2017].

[5] M. J. Yim, Y. Li, K. Moon, K. W. Paik, and C. P. Wong, "Review of Recent Advances in Electrically Conductive Adhesive Materials and Technologies in Electronic Packaging," J. Adhes. Sci. Technol., vol. 22, no. 14, pp. 1593-1630, 2008.

[6] Y. C. Lin and J. Zhong, "A review of the influencing factors on anisotropic conductive adhesives joining technology in electrical applications," J. Mater. Sci., vol. 43, no. 9, pp. 3072-3093, 2008.

[7] G. Schiavone et al., "A highly compact packaging concept for ultrasound transducer arrays embedded in neurosurgical needles," Microsyst. Technol., pp. 1-11, 2016.

[8] G. Schiavone et al., "Advanced electrical array interconnections for ultrasound probes integrated in surgical needles," Proc. 16th Electron. Packag. Technol. Conf. EPTC 2014, pp. 88-93, 2014.

[9] C.-M. Lin, "Effects of Pad Array Dimensions and Misalignment Offsets on Optimal Fraction of Conductive Particles in Anisotropic Conductive Film Packages," IEEE Trans. Device Mater. Reliab., vol. 13, no. 1, pp. 301-309, Mar. 2013.

[10] Y. C. Lin and X. Chen, "Reliability of Anisotropic Conductive Adhesive Joints in Electronic Packaging Applications," J. Adhes. Sci. Technol., vol. 22, no. 14, pp. 1631-1657, 2008. 